\title{
Hacia una nueva historia del arte: desmitificación de los conceptos estilísticos del arte novohispano del siglo XVI*
}

Rie ARIMURA

Hoy en día existe una reflexión profunda en torno a la historiografía tradicional del arte, por lo que se ha realizado el análisis de los textos con el fin de detectar los problemas del estado actual de la investigación. Además, la identificación de los problemas de nivel teórico, metodológico e interpretativo conduce a replantear un nuevo marco de estudio, como afirma Bauer: la historiografía es una rama de las humanidades que se ocupa de analizar diferentes marcos teóricos, métodos, epistemologías y conciencias humanas que ha habido sobre el mismo tema y además, atiende el problema de la sistematización de datos para plantear nuevas posibilidades de ordenación (Bauer 1980: 11-13).

Uno de los puntos más discutidos en las últimas décadas acerca de la comprensión tradicional de la historia del arte es, sin duda, la sistematización de datos con base en el empleo de la terminología estilística. Al respecto, cabe recordar que la taxonomía de estilos responde a la idea ilustrada de clasificarlo todo como hizo Darwin con sus especies biológicas, así como a la herencia positivista de aproximarse al fenómeno con una visión esquemática.

Antes de abordar el problema de las consideraciones estilísticas, es oportuno puntualizar que en el ámbito de la crítica artística el término "estilo" se ha empleado en dos sentidos. La primera idea de estilo, como cualidad inherente y personal, tiene su origen en la maniera, vocablo empleado por Giorgio Vasari a mediados del siglo XVI, mientras que el concepto de estilo aplicado en el sentido histórico-cronológico surge hasta el siglo XIX con Viollet-le-Duc. Esta segunda idea de estilo, que sirve para clasificar las obras de arte por periodos, se fundamenta en la creencia de la uniformidad estilística 
en las manifestaciones artísticas de una época. No obstante, al mismo tiempo existe una contracorriente como la de Herder:

¡Cómo se apodera siempre de mí el temor cada vez que oigo caracterizar a toda una nación o época en pocas palabras, ya que cuán inmensa es la masa de variantes comprendida en palabras tales como nación o Edad Media o tiempos antiguos y modernos!

(Herder, citado por Gombrich 1980: 251)

Con el avance de las investigaciones en el siglo XX, también en el área de la Historia del Arte, se ha observado la diversidad y heterogeneidad artística de un periodo histórico, por lo cual, se ha apuntado la debilidad de clasificar el complejo fenómeno cultural-artístico con base en el concepto de estilos históricos. En el nivel internacional. Gombrich ha señalado que la categoría estilística no es sino una hipótesis, puesto que se encasilla la obra en un concepto a priori, pero cada objeto artístico es tan propio y tan individual que cuanto más se estudia la obra, se manifiesta lo inadecuado de la categoría estilística. Por lo mismo, dicho autor postula la neutralidad y relatividad de los conceptos estilísticos (Gombrich 1984: 185-217).

En el caso de la historiografía del arte novohispano también se presenta el mismo problema. Debido a la carencia de un método propio para estudiar y escribir sobre las artes originadas en México, la historia del arte virreinal se ha concebido con el mismo esquema de sistematización de datos que la historia del arte europeo, por consiguiente, está construido con base en los preceptos utilizados en la historiografía de este último. Lo anterior ha conducido a que los historiadores del arte novohispano redefinan tales preceptos o conciban otras nomenclaturas (Gutiérrez 2001: 90-92). Pese a los esfuerzos, aún siguen presentes las confusiones y discusiones en torno a los términos estilísticos. Con respecto a esta cuestión, cabe citar las referencias de Kubler, quien apunta la deficiencia de los conceptos estilísticos para el estudio del arte virreinal:

Todo varía con el tiempo y el lugar, y no podemos fijar en ninguna parte 
una cualidad invariable, como hace suponer la idea de estilo, incluso cuando separamos las cosas de sus lugares. Pero cuando se tienen en cuenta la duración y el marco, tenemos en la vida histórica relaciones variables, momentos pasajeros y lugares cambiantes en la vida histórica. Cualquier dimensión o continuidad imaginaria, como el estilo, se desvanece de la vista cuando las buscamos.

(Kubler 1975: 154)

McAndrew, compartiendo la opinión con Kubler, afirma que los conceptos estilísticos del arte occidental, que ni siquiera son aptos para el arte español, sirven menos para el novohispano debido a las disparidades cronológicas y genealógicas que se presenta en el último arte (McAndrew 1965: 170). Manrique, por su parte, reconoce que el estilo es "una ficción conceptual" y toda definición estilística es "violadora de la realidad", aunque sirve de herramienta para confrontar los hechos reales (Manrique 2001: 237).

A pesar de estos cuestionamientos que ha habido en torno a la terminología estilística, la postura de aplicar el concepto de estilos históricos en las interpretaciones del arte virreinal permanece vigente. Aunque también es cierto que en busca de una nueva historia del arte, en la actualidad existen publicaciones que ya no abordan la historia de las manifestaciones visuales en forma de secuencia cronológica estilística. Por citar un ejemplo, Hacia otra historia del arte plantea una aproximación al arte según los contenidos discursivos de las imágenes (Acevedo 2001).

El presente trabajo tiene como objetivo mostrar el problema del reconocimiento de las herencias artísticas virreinales del siglo XVI en el nivel historiográfico. (Al respecto, vale la pena agregar que cada autor está respondiendo a su tiempo, por lo que sus afirmaciones son productos de las circunstancias históricas.) Para ello, expongo a guisa de introducción un panorama sobre el empleo de los términos estilísticos en la historiografía del arte virreinal del siglo XVI y después examino las controversias estilísticas de los conjuntos arquitectónicos de Yanhuitlán y Yuriria. De tal forma que pretendo comprobar la hipótesis de que la naturaleza del arte novohispano es tan compleja y presenta una serie de disparidades cronológicas y genealógicas con respecto al criterio del arte europeo que la interpretación tradicional 
basada en las taxonomías estilísticas esquemáticas no ofrece suficiente cabida para explicar las hechuras virreinales, al contrario, obstruye la comprensión correcta de las mismas.

\section{Un panorama sobre el empleo de los términos estilísticos en la historiografía del arte novohispano del siglo XVI}

La historia del arte en México se origina en el contexto nacionalista decimonónico con el motivo de definir la identidad y legitimar el nivel cultural del país. En el área virreinal, Revilla, Baxter, Romero de Terreros, Toussaint, Angulo y Kubler son pioneros en las investigaciones artísticas y comienzan a introducir y adaptar los términos estilísticos europeos al interpretar el arte en cuestión. A esto, cabe agregar que la postura eurocéntrica no radica sólo en la ordenación de datos, sino también en el aparato crítico. En efecto, los citados autores se basan en las crónicas hispanas sin dudar la veracidad, ya que casi no contemplan documentos ni mucho menos fuentes indígenas. Mas, esta aproximación eurocéntrica tiene aceptación amplia en su tiempo, dado que a los albores de la construcción de la historia del arte novohispano, la asociación e identificación de las herencias europeas y su consecuente uso terminológico han sido útiles para elevar y legitimar el valor artístico de las creaciones americanas. En ese sentido, el eurocentrismo juega un papel importante en la justificación teórica del discurso cultural-artístico del país.

\section{¿La arquitectura del periodo primitivo "sin estilo"?}

En la historiografía del arte novohispano de la primera mitad del siglo XX se ha hablado de que antes de la introducción de los "estilos medievales" se levantaron las construcciones "sin estilo" y "carentes de sentido estético". Los autores que sostienen este postulado son Revilla, Baxter y Toussaint. El primero apunta la carencia de la elegancia afirmando que: "Las primeras manifestaciones son toscas a raíz de que sólo satisfacían las necesidades más urgentes antes que al buen gusto y a la perfecta comodidad" (Revilla 1893: 20; 1923: 29). Asimismo, Baxter menciona: "Los conquistadores y los frailes de la primera generación no tuvieron inclinación ni medios para construir con 
anhelos estéticos" (Baxter 1934: 23). En opinión de Toussaint, la primera arquitectura de México fue "improvisada" y "sin estilo" (Toussaint 1935: 47). Con relación a estas afirmaciones, quiero advertir que la arquitectura del tiempo primitivo era de materiales perecederos como madera y adobe. En la actualidad no quedan vestigios, sino que sólo se conoce por medio de las fuentes. Por lo mismo, no hay manera de juzgar el valor creativo de dichas hechuras ni mucho menos evaluarlas con algún calificativo como "tosco". Además, a mi juicio, el hecho de que las circunstancias históricas no les permitieron levantar edificios majestuosos no implica de manera alguna que los constructores del primer tiempo no hayan tenido sentido o anhelos estéticos.

\section{Cambios epistemológicos e introducción de diferentes conceptos estilísticos}

En el porfiriato Revilla y Baxter interpretan el arte conventual del siglo XVI sólo tomando en consideración los ejemplos franciscanos ubicados en la Altiplanicie Central de México. Pese a que observan la presencia de las reminiscencias artísticas "medievales", no emplean el término "románico", sino sólo el "gótico" señalando una sola característica: las bóvedas con nervaduras (Revilla 1893: 21; Baxter 1934: 24). No obstante, ambos autores identifican a la vez el aspecto masivo, el uso de contrafuertes y almenas-que hoy suele considerarse como características arquitectónicas "románicas", aunque con respecto a las almenas, se ha señalado también antecedente prehispánico (Kubler 1984: 538)—. En efecto, Revilla apunta los caracteres "tosco" y "fuerte" (Revilla 1893: 21), mientras que Baxter indica el aspecto "militar" y "defensivo" de la arquitectura conventual franciscana (Baxter 1934: 24).

Para designar este arte que presenta a la vez una herencia "gótica" y aspectos "tosco", "defensivo" y "militar", Baxter acuña el término estilístico "franciscano primitivo". Es sugerente que esta nomenclatura descanse sobre la tesis de que las obras de la misma orden religiosa comparten características y además, el autor haya mostrado la preferencia de sistematizar las obras virreinales según la orden religiosa, en vez de los conceptos puramente 
formales. No obstante, el término acuñado por Baxter no tiene aceptación amplia, ya que Mariscal es el único que retoma dicho concepto (Mariscal 1915: 53, 58). A mi entender, esto se debe a la falta de definición conceptual, ya que el término deja mucha ambigüedad a raíz de que nunca se ha teorizado ni puntualizado lo distintivo del "franciscano primitivo".

Si bien este término no ha sido eficiente para la taxonomía estilística, la postura de establecer relaciones artísticas entre las hechuras de la misma orden religiosa de determinado tiempo ha sido trascendente y, a mi juicio, tiene una lógica, dado que los mismos frailes intervinieron en varias obras constructivas de su orden, como fray Francisco Marín, en la Mixteca, Oaxaca. Por lo mismo, no sólo los precursores como Romero de Terreros, Toussaint y Angulo, sino también los investigadores contemporáneos como Mullen y Vargas Lugo han aplicado una aproximación comparativa entre las obras de la misma orden. Incluso, en el caso de Angulo, agrupa las obras conventuales de la misma orden de la misma región geográfica con el concepto de "escuela".

Si bien la aplicación de las taxonomías estilísticas occidentales comienza con los autores decimonónicos, el afán de introducir términos estilísticos se distingue de manera notable en los estudiosos de generación posrevolucionaria como Romero de Terreros y Toussaint. En el trasfondo se da un avance de las investigaciones gracias a la nueva política cultural nacionalista. Incluso, a partir de la década de 1930 los estudiosos comienzan a contar con apoyos institucionales. Es decir, se crean las instalaciones para la investigación como el Laboratorio de Arte, antecedente del Instituto de Investigaciones Estéticas (IIE) de la UNAM, además del Departamento de Monumentos Coloniales del INAH, que se hace cargo de la custodia, preservación, estudio y difusión del patrimonio cultural de México.

Toussaint, figura central dentro de las citadas instituciones, es el primero en sistematizar extensos datos del arte virreinal, ya que su estudio abarca la arquitectura, escultura y pintura de todo el virreinato. Para ello, el autor somete dichas manifestaciones americanas al tradicional esquema europeo dividiéndo el tiempo en tres edades: "antigua", "media" y "moderna". En el caso de México, desde el siglo XIX ha habido la postura de considerar el periodo prehispánico como "antiguo", mientras que a partir de la época 
novohispana México entra al tiempo "medieval" y "moderno". No obstante, las delimitaciones cronológicas de estos últimos dos periodos han sido ambiguas y contradictorias. En efecto, Toussaint mismo cae en una paradoja: por una parte, propone: "Edad Media en México" (1519-1550) y el "Renacimiento en México" (1550-1630) (Toussaint 1983: 1), pero, por otra parte, asevera la presencia de elementos "medievales" en las obras novohispanas de la segunda mitad del siglo XVI. Así, el intento de Toussaint de ajustar los fenómenos virreinales al esquema europeo se termina sin éxito.

El reconocimiento de diversas herencias artísticas novohispanas ha hecho trasformar la conciencia de los investigadores de esa época. Para denominar diferentes tradiciones plásticas, Toussaint y Romero de Terreros optan por introducir conceptos estilísticos creados para el arte hispano de los siglos XV-XVI: "isabelino", "plateresco" y "herreriano". El empleo de "plateresco" para las fachadas agustinas novohispanas ha sido una ruptura interpretativa con respecto al postulado anterior de Revilla: “... no vemos entre los edificios aquí erigidos en el siglo XVI muestras de aquel elegante estilo plateresco que floreció en España durante el gobierno de Carlos V" (Revilla 1893: 21). La introducción de varios términos estilísticos implica, para su momento, una nueva postura historiográfica en contra de la tendencia generalizadora de agrupar todo el fenómeno artístico virreinal con el término de "estilo colonial" (Romero 1951: 9). En suma, la clasificación estilística ha sido, en un principio, una manera de legitimar la riqueza artística de México.

Sin embargo, el empleo de conceptos estilísticos genera a la vez un problema. Debido a que los estudios del arte en México no surgen como teoría, sino como historia adaptada al esquema europeo sin puntualizar el marco teórico, desde su comienzo se ha presentado una serie de incongruencias en la sistematización de datos. Es decir, en la primera mitad del siglo XX, pocos autores como Toussaint, Moreno Villa definen las categorías estilísticas; los postulados de éstos no muestran claridad y coherencia; los demás estudiosos no siguen de manera fiel los criterios establecidos por los autores referidos, sino que utilizan los términos de manera arbitraria sin hacer aclaración alguna. 


\section{Reflexiones historiográficas y redefinición de los términos estilísticos}

A partir de las décadas de 1960-1970, con la mayor difusión de las teorías de la Historia del Arte en el ámbito mexicano, se dan cambios radicales tanto en el marco teórico-metodológico como en los postulados académicos. En esta época los investigadores parten del cuestionamiento sobre la historiografía tradicional, como ha hecho Ramírez Romero con respecto a las taxonomías de lo "español" y lo "indígena". Además, atienden problemas y redefinición de los términos estilísticos, en especial, "manierismo", "tequitqui" e "indocristiano". Para esta tarea, se destacan Vargas Lugo, Manrique, Ruíz Gomar, Fernández y Reyes-Valerio.

\section{¿Taxonomías: “español” e "indígena” o "culto" y “popular”?}

Ramírez Romero critica la arbitrariedad de los juicios para indicar la autoría de las obras virreinales, ya que el trabajo "bien hecho" se atribuía, sin sustento alguno, a las manos españolas y el "mal hecho", a las indígenas (Ramírez 1966: 158). Con relación a esto, es oportuno indicar que en la época virreinal, los trabajos artísticos se produjeron de manera colectiva. La mayor parte de la mano de obra fue de los nativos, puesto que los maestros europeos dirigieron las obras o se encargaron de elaborar las partes más importantes. De ser así, ¿qué tanto se puede atribuir las producciones de buena calidad exclusivamente a los europeos?

Asimismo, esta distinción arbitraria de las manufacturas "español" e "indígena" estuvo íntimamente relacionada con las categorías de "culto" y "popular". Como es sabido, la clasificación basada en dichos conceptos deriva de la crítica de las lenguas, por lo que se le llama Vulgata a la Biblia que san Jerónimo tradujo al latín, lengua "vulgar" en aquel entonces. Esta taxonomía lingüística ha sido adaptada más tarde en la crítica artística e incluso, deja un impacto en los calificativos estilísticos del arte novohispano. De tal forma que se crean términos como "plateresco culto" y "plateresco popular".

En la historiografía del arte virreinal, el vocablo "plateresco" se ha empleado, por excelencia, para apreciar la arquitectura agustina. En efecto, desde Romero de Terreros, Toussaint y Angulo hasta los investigadores contemporáneos como Vargas Lugo han calificado la portada del templo de 
Acolman de "plateresco culto", "plateresco puro" o "plateresco español", mientras que la de Yuriria, de "plateresco popular" o "plateresco popular indígena". De tal forma se ha menospreciado el valor plástico de esta fachada en comparación con aquélla. A partir de lo anterior se deduce que el "popular", "indígena" y "malo" son conceptos ligados estrechamente.

Sin embargo, en sentido estricto de la palabra, "popular" e "indígena" no han implicado lo mismo, toda vez que la identificación de lo "indígena" ha sido aprovechada en gran medida para la legitimación de la personalidad artística novohispana, ya que no siempre tiene connotación negativa. Al contrario, este concepto ha sido apreciado al menos en nivel teórico para la conveniencia del discurso cultural de la nación. Pero, también es cierto que en la praxis, los mismos intelectuales y académicos han menospreciado el valor artístico de las expresiones del pueblo americano. Así que las obras que no van acorde con los cánones occidentales se han considerado como producciones sin "ningún valor artístico" (Toussaint 1962: 20). En resumen, atrás del concepto "indígena" existen una serie de contradicciones ideológicas.

La interpretación basada en los conceptos taxonómicos "popular" e "indígena" ha generado ambigüedad en la crítica del arte virreinal debido a que no se ha conceptualizado de manera clara con excepción de Angulo, para quien, la manufactura "indígena" consistía en la simplificación de los planos y la geometrización de las formas (Angulo 1982: 358). Desde mi punto de vista, estas categorías estilísticas: "español" e "indígena" o "culto" y "popular", frutos del eurocentrismo y esquematización, han sido un arma de doble filo. Por una parte, han legitimado el nivel artístico de México estimando las hechuras que presentaban mayor similitud al arte europeo. Pero, al mismo tiempo, ha hecho descalificar aquellas hechuras concebidas de acuerdo con las tradiciones plásticas locales.

En el caso de la portada de Yuriria, los autores del siglo XX la han menospreciado en cierta medida poniéndole el calificativo "popular" si esta hechura era "suntuosa" o “... la primera maravilla de las fábricas de la Nueva España” para los habitantes de la época como afirma Basalenque en 1673. En resumidas cuentas, la postura eurocéntrica no respeta ni rescata la visión de las personas que crearon y utilizaron las hechuras, sino que se aproxima a las 
obras desde una perspectiva contemporánea unilateral. Así, ha hecho distorsionar la apreciación de la obra en lugar de reconstruir e interpretar de manera correcta el significado que el objeto tuvo en su contexto original.

\section{Introducción y adaptación del concepto "manierismo"}

Una gran novedad en las consideraciones estilísticas de las décadas 19601970 es la introducción y aplicación del vocablo "manierismo". Al respecto, cabe recordar que si bien el surgimiento, revalorización y teorización del "manierismo" comienza a realizarse junto con el surgimiento del expresionismo alemán en Europa a principios del siglo XX (ya que este último movimiento vanguardista encuentra su justificación estética en las obras del Cinquecento, denominadas hoy "manieristas"), en la historiografía del arte novohispano, la aplicación del término "manierismo" no se da sino hasta 1962, cuando Baird lo introduce por vez primera (Baird 1962). En la década de 1970 Manrique redefine el concepto en el estudio de las catedrales de México y Puebla.

Esta introducción y adaptación de "manierismo" de los años 60-70 es una repercusión del XX Congreso Internacional de la Historia del Arte celebrado en Nueva York en 1961. En este evento Gombrich y Shearman han desmitificado la consideración tradicional del "manierismo": expresión de "crisis", idea propuesta por Hauser y Antal, postulando un nuevo concepto "virtuosismo artístico" de acuerdo con el sentido original de maniera (Gombrich 1963). (Los citados estudiosos alemanes, que se apoyaron en el marco teórico de la sociología del arte, habían distorsionado los significados de las obras "manieristas" aseverando que éstas manifiestaban "crisis", ya que eran frutos de un contexto en que la península itálica vivía conflictos políticos, económicos y sociales.)

En la teoría de Manrique, el "manierismo" corresponde a la última fase del Renacimiento, en la que se interpreta el ideal de "perfección" alcanzado por los grandes artistas italianos. Asimismo, esta corriente artística se divide en dos fases: la primera se llama "manierismo en strictu sensü", en que se pretende aplicar las reglas "perfectas", según la consideración de la época y este estilo coincide cronológicamente con el fenómeno establecido por la 
Reforma Católica o "Contrarreforma", mientras que la segunda es "manierismo avanzado" donde los artistas tratan de ir más allá de las reglas ideales creadas en el Renacimiento (Manrique 2001). Para este autor, todo aquel fenómeno derivado de las tradiciones artísticas del Cinquecento pero dado fuera de la península itálica-incluye España y América-es "manierismo". Así, propone un cambio teórico-terminológico en lugar del "estilo greco-romano puro" de Revilla, "herreriano" de Toussaint y Romero de Terreros y "Renacimiento" de Baxter, Angulo y De la Maza. El postulado de Manrique ha sido aceptado ampliamente dentro del círculo del IIE, UNAM. Incluso, Ruíz Gomar desarrolla las ideas del maestro para aplicar el mismo concepto en el estudio de la pintura novohispana. No obstante, los investigadores que no pertenecen a la UNAM como Tovar de Teresa no respetan el criterio de Manrique, sino que optan por el término "Renacimiento". Así, el desacuerdo y arbitrariedad están sin resolverse.

\section{Controversias estilísticas de los conventos de Yanhuitlán y Yuriria}

En el nivel historiográfico, existe una discrepancia de opiniones en las consideraciones estilísticas del conjunto arquitectónico de Yanhuitlán. A juicio de Toussaint: “... el templo de Yanhuitlán es un monumento de primer orden que podría encontrarse en cualquier ciudad europea..." (Toussaint 1983: 52) y el convento "parece" como un edificio "románico", aunque “... no es una fortaleza como los templos franciscanos porque hasta la cerca almenada del atrio ha desaparecido..." (Toussaint 1962: 19). Aquí Toussaint asocia el convento de Yanhuitlán con la idea de "románico" de acuerdo con su percepción inmediata. Pero, no asevera que lo es, sino "parece". Su opinión deja mucha ambigüedad pero hay que tener presente que el autor expone su punto de vista en el texto llamado Paseos coloniales (1939). A saber, la intención del autor no radica en escribir una monografía pura, sino un ensayo que muestra los registros del viaje realizados desde los años 20 , así como experiencias estéticas personales y descripciones con el motivo de difundir el conocimiento general de los inmuebles virreinales. Es decir, es un texto en que se mezclan las apreciaciones literario-alegóricas y registros académicos.

Por otra parte, con respecto a la afirmación: “... hasta la cerca almenada 
del atrio ha desaparecido...", Toussaint postula la ausencia de la barda atrial con almenas en el conjunto conventual de Yanhuitlán. Pero cabe advertir que la barda de tal carácter sí estuvo originalmente ahí, ya que lo refieren tanto el padre Cobo como Burgoa en el siglo XVII. Lo cierto es que la barda en cuestión ha sido eliminada en una fecha indeterminada. (Tal vez se reutilizó parte del antiguo muro cuando el convento se convirtió en la fortificación de San Fernando durante la guerra de Independencia al finalizar la época virreinal, mientras que la barda sin almenas que vemos hoy data de 1908. Al menos, así se registra en un sillar del acceso norte del atrio) (referencias proporcionadas por González Leyva 2008). En mi apreciación, el problema del juicio de Toussaint-y también de muchos otros autores-radica en juzgar el estilo con base en una observación parcial y superficial, dado que postula un cambio estilístico entre la arquitectura franciscana y la dominica tomando en cuenta un solo elemento: almenas, cuando una obra arquitectónica se conforma con diversos elementos.

Por el contrario del calificativo "románico" de Toussaint, dicho convento dominico no presenta ninguna herencia de la Baja Edad Media. Por lo tanto, los estudiosos posteriores han calificado de la siguiente manera: "gótico" para la bóveda de nervadura, "plateresco" para la portada-norte y "herreriano", "renacentista" o "barroco sobrio" para la portada principal del templo. Gorbea Trueba, por su parte, detecta que la técnica constructiva de Yanhuitlán se diferencia del sistema estructural "ojival". Es decir, en este último sistema constructivo, la piedra de corte soporta por sí sola sus techumbres y los vanos predominan sobre los muros, mientras que en Yanhuitlán, hay más muros que vanos. Además, dichos muros están conformados con dos paramentos de piedra cortada rellenos con mampostería corriente o dicho de otra manera, “... una gruesa mampostería pegada con fuerte argamasa a la que se adhieren los sillares aparentes" (Gorbea 1962: 13, 26). (Esta solución constructiva está presentada como sistema de "cascajos" o "a cajón" en el tratado de arquitectura del Renacimiento.) A partir de esta observación, el citado investigador postula que en Yanhuitlán se une en cierta forma los sistemas estructurales "romano" y "ojival"—aquí, el autor utiliza los conceptos "romano" y "ojival" como sinónimos de "renacentista" y "gótico" 
respectivamente-(Ibid:: 26).

En mi opinión, esta observación de Gorbea Trueba nos conduce a una reflexión. Desde Toussaint se ha aproximado al convento con una visión eurocéntrica y esquemática aplicando la terminología estilística europea. En el caso de la estructura del templo, se ha identificado la mayoría de veces con el concepto "gótico" al ver simplemente bóvedas de nervadura. No obstante, Gorbea Trueba mismo demuestra que la naturaleza artística novohispana es tan compleja que se distingue de la europea. Es decir, la apropiación de diferentes tradiciones no consiste sólo en la parte superficial compositivodecorativa como señala Angulo, sino también en los materiales y técnicas constructivos. Asimismo, hay que tener presente que el diseño conventual está adaptado al medio ambiental de América; además, el convento tiene distintas etapas constructivas y alteraciones de diferentes siglos. Frente a estas disparidades cronológicas y genealógicas, ¿cómo vamos a calificar de manera "correcta" el estilo del convento?

\section{El mito de "convento-fortaleza"}

Una consideración que se ha legitimado acerca de los conventos novohispanos es la idea de "convento-fortaleza". En el nivel historiográfico, Revilla y Baxter comienzan a plantear dicho concepto para la apreciación arquitectónica franciscana apoyándose sobre la referencia de Cervantes de Salazar, quien describe, en 1554, los edificios de la ciudad de México de la manera siguiente: "Según su solidez, cualquiera diría que no eran casas, sino fortalezas" (Cervantes 1991: 42). Toussaint, por su parte, retoma y aplica la idea de "convento-fortaleza" para la arquitectura de otras órdenes como el convento de Yuriria (Toussaint 1983: 48). Para fundamentar su argumento, se basa en Grijalva y Escobar, ya que estos cronistas abordan la necesidad de defender el convento de los ataques chichimecas: el templo era “... un formidable castillo desde donde se defendían de los chichimecos los naturales de este pueblo" (Escobar 1970: 309). Este postulado se ha aceptado ampliamente. A lo anterior Kubler agrega que el ancho de los muros de Yuriria se debe quizá a una razón militar (Kubler 1984: 184). Gante, incluso, llega a proponer el término de "estilo monástico-militar" (Gante 1954: 72). 
Por otra parte, existe la corriente de interpretar el aspecto defensivo de los conjuntos conventuales virreinales en sentido espiritual, ya que éstos simbolizan la "fortaleza espiritual de la Iglesia militante y la prefigura tradicional de la Jerusalén Celeste" (Estrada 1986: 637; Fernández 2003: 73). Así, esta postura plantea que el legado medieval del arte conventual novohispano se debe al factor simbólico-litúrgico.

Todas estas ideas han sido construidas a partir de la presencia de almenas en la arquitectura conventual y se ha definido la idea de "convento-fortaleza" como rasgo distintivo de los conventos virreinales del siglo XVI. Sin embargo, todo esto ha sido un mito, ya que en la última investigación de los procesos constructivos de Yuriria, se ha detectado que las almenas que vemos ahora son hechuras agregadas en el siglo XVIII (González Leyva 2008: cap. V). ¿A este fenómeno vamos a seguirle llamando "románico" o expresión de la "Edad Media en México"?

\section{Consideraciones finales y preguntas por resolver}

La aproximación esquemática, superficial y eurocéntrica, así como la arbitrariedad y abuso de los conceptos estilísticos han hecho distorsionar la compresión de las obras virreinales. Con todo, a mi entender, los problemas expuestos aquí no son exclusivos de la historiografía del arte de México, sino de muchas partes del mundo-inclusive Japón o aun la misma Europa-, dado que desde el siglo XIX los países que quedan fuera de los centros artísticos europeos se han visto obligados a sistematizar e interpretar expresiones artísticas propias sometiéndolas y encajándolas a un esquema a priori.

Tanto en Europa como en México la variedad de los términos estilísticos surgen con el avance de las investigaciones, ya que el reconocimiento de la diversidad de los fenómenos artísticos genera la necesidad de sistematizar las obras de manera más minuciosa. Así, se han creado o adaptado nuevas nomenclaturas. No obstante, el mismo avance de la investigación conduce a los especialistas de la segunda mitad del siglo XX a reflexionar sobre los problemas y límite de la aproximación e interpretación de la historia del arte basada en las taxonomías estilísticas. Al respecto Kubler menciona: 
... debemos reconocer que el concepto o noción de estilo es propio de nuestro tiempo y que, a veces, cuando se trata de aplicar a formas artísticas de regiones geográficas lejanas es totalmente inoperante (Kubler, citado por Victoria 1986: 51).

¿Por qué vamos a seguir utilizando los términos estilísticos, que los mismos autores del siglo XX han reconocido como "ficción o violador de la realidad"? No debemos perder de vista que el objetivo central del estudio del arte no radica en clasificar la obra en alguna taxonomía estilística, ya que éste no es más que una herramienta para confrontar la obra.

A diferencia del tiempo de los precursores del estudio del arte, estamos en una época en la que tenemos la obligación de presentar un estudio exhaustivo con la mayor precisión posible sin dejar ninguna ambigüedad conceptual. Ante esta necesidad, los reducidos y esquemáticos conceptos estilísticos nos obstaculizan construir un conocimiento científico con rigor. ¿Ya no será el momento de dejar esta aproximación tradicional del arte y hacer una nueva propuesta para estudiar y escribir sobre la obra?

*Esta revisión historiográfica se realizó dentro de los marcos de los proyectos interdisciplinarios CONACYT-SEP-2004-C01-47642, PAPIIT IN402603 y PAPIIT IN403606-2, dirigidos por la doctora Alejandra González Leyva (FFyL, UNAM) y muestra las conclusiones que he adquirido a través del estudio sobre la terminología estilística del arte europeo y novohispano. La idea central de no emplear términos estilísticos en el estudio del arte fue desarrollada con base en la discusión que tuve con la citada doctora. Debido a lo anterior, nuestro equipo interdisciplinario hemos optado por interpretar los procesos constructivos y el ajuar interior de los conjuntos arquitectónicos conventuales de Tlaxcala, Yuriria y Yanhuitlán sólo ubicándolos en el tiempo y el espacio. Para la descripción de las características constructivas, decidimos respetar los términos que aparecen en los tratados de arte y arquitectura de la época. 


\section{Bibliografía}

Acevedo, Esther (coordinadora), Hacia otra historia del arte en México. De la estructuración colonial a la exigencia nacional, México, CONACULTA, 2001, t. I.

Angulo Iñiguez, Diego, Historia del arte hispanoamericano (1945), México, Instituto de Estudios y Documentos Históricos, A. C., 1982, t. I.

Basalenque, Diego de, Historia de la provincia de San Nicolás Tolentino de Michoacán del orden de N.P.S. Agustín (1673), introducción, selección de textos y notas de Heriberto Moreno García, México, Jus, 1963.

Baird, Joseph Armstrong, Jr., The Churches of Mexico 1530-1810, Berkeley, Los Angeles, University of California Press, 1962.

Bauer, Hermann, Historiografía del arte, Madrid, Taurus, 1980.

Baxter, Silvestre, La arquitectura hispano colonial en México (1901), México, [s.e.], 1934.

Cervantes de Salazar, Francisco, México en 1554 y túmulo imperial (1554), México, Porrúa, 1991 ("Sepan cuantos ...", 25).

Escobar, Matías de, Americana Thebaida (1729), Morelia, Balsal Editores, 1970.

Estrada de Gerlero, Elena Isabel, "Sentido político, social y religioso en la arquitectura conventual novohispana" (1982), en Historia del arte mexicano, México, SEP, Salvat, 1986, t. 5: Arte colonial I.

Fernández, Martha, Historia del concepto de "arte tequitqui", tesis de licenciatura en Historia, México, UNAM, FFyL, 1976.

_- La imagen del templo de Jerusalén en la Nueva España, México, UNAM, 2003.

Gante, Pablo C. de, La arquitectura de México en el siglo XVI, México, Porrúa, 1954.

Gombrich, Ernest H., El sentido de orden, Barcelona, Gustavo Gili, 1980.

—, Norma y forma, Madrid, Alianza, 1984.

Gombrich, Ernst H. et al., The Renaissance and Mannerism. Studies in Western Art. Acts of the Twentieth International Congress of History of Art, Princeton, New Jersey, Princeton University Press, 1963.

González Leyva, Alejandra, Yuriria: construcción, historia y arte de un convento agustino, México, UNAM, Facultad de Filosofía y Letras, 2008.

Gorbea Trueba, José, Yanhuitlán, México, INAH, Departamento de Monumentos Coloniales, 1962.

Gutiérrez Haces, Juana, “Algunas consideraciones sobre el término 'estilo' en la historiografía del arte virreinal mexicano", en El arte en México: autores, temas, problemas, México, CONACULTA, Lotería Nacional, FCE, 2001. 
Kubler, George, La configuración del tiempo, Madrid, Alberto Corazón Editor, 1975.

—-, Arquitectura mexicana del siglo XVI (1948), México, FCE, 1984.

Manrique, Jorge Alberto, Una visión del arte y de la historia, México, UNAM, IIE, 2001, t. III.

Mariscal, Federico E., La patria y la arquitectura nacional, México, Imprenta Stephan y Torres, 1915.

Maza, Francisco de la, "Panorama del arte colonial de México", en Cuarenta siglos de plástica mexicana, México, Editorial Herrero, 1970.

McAndrew, John, The Open Air Churches of Sixteenth Century Mexico, Cambridge, Massachussets, Harvard University Press, 1965.

Mullen, Robert James, Dominican Architecture in Sixteenth-century Oaxaca, Phoenix, Arizona, Center for Latin American Studies, Arizona State University, Friend of Mexican Art, 1975.

Ramírez Romero, Esperanza, Un ensayo crítico sobre el convento de Yuriria, tesis de maestría en Historia del Arte, México, Universidad Iberoamericana, 1966.

Revilla, Manuel G., El arte en México en la época antigua y durante el gobierno virreinal, México, Secretaría de Fomento, 1893.

—_, El arte en México, México, Porrúa, 1923.

Romero de Terreros, Manuel, Historia sintética del arte colonial de México (15211821), México, Porrúa, 1922.

_- El arte en México durante el virreinato, México Porrúa, 1951.

Reyes-Valerio, Constantino, Arte indocristiano. Escultura del siglo XVI, México, ENCRM, SEP, 1978.

__, "El arte indocristiano o tequitqui", en Historia del arte mexicano (1982), México, SEP, Salvat, 1986, t. 5: Arte colonial I.

Romero de Terreros, Manuel, Historia sintética del arte colonial de México (15211821), México, Porrúa, 1922.

—, El arte en México durante el virreinato, México, Editorial Porrúa, 1951.

Ruíz Gomar, José Rogelio, Un panorama y dos ejemplos de la pintura mexicaba en el paso del siglo XVI al XVII, tesis de licenciatura en Historia, México, UNAM, FFyL, 1979.

Toussaint, Manuel, "Supervivencias góticas en la arquitectura mexicana del siglo XVI", en Archivo Español de Arte y Arqueología, núm. 31, Madrid, 1935.

_- Paseos coloniales (1939), México, UNAM, IIE, 1962.

_, Arte colonial en México (1948), México, UNAM, IIE, 1983.

Tovar de Teresa, Guillermo, Pintura y escultura del Renacimiento en México, México, 
INAH, 1979.

Vargas Lugo, Elisa, Las portadas religiosas de México, México, UNAM, IIE, 1969.

Vasari, Giorgio, Las vidas de los más excelentes arquitectos, pintores y escultores italianos desde Cimabue a nuestros tiempos, Madrid, Editorial Tecnos, 1998.

Victoria, José Guadalupe, Pintura y sociedad en Nueva España. Siglo XVI, México, UNAM, IIE, 1986. 
$<$ Resumen $>$

\section{Hacia una nueva historia del arte: desmitificación de los conceptos estilísticos del arte novohispano del siglo XVI}

Rie ARIMURA

La teoría, metodología y conocimiento de la Historia del Arte construidos desde la Ilustración han sido víctimas del eurocentrismo y criterio unilateral esquemático. El tradicional marco teórico-metodológico ha sido ineficiente para interpretar nuestro complejo mundo visual. Por lo mismo, en la actualidad se ha propuesto incluso que el término "historia del arte" constituye en sí mismo un anacronismo o se ha hablado del "fin" de la historia del arte. Ante estas nuevas consideraciones de nivel internacional, los investigadores de hoy intentan liberarnos de la parte negativa de nuestra herencia del pasado procurando renovar de manera radical los estudios del fenómeno artísticoestético.

La idea de estudiar los problemas de términos estilísticos ha surgido a partir del cuestionamiento: ¿cómo podemos renovar las interpretaciones de las manifestaciones plásticas sin destruir totalmente las tradiciones de la disciplina académica: Historia del Arte? El presente ensayo propone como una alternativa la postura de estudiar e interpretar las obras sin utilizar términos estilísticos, los cuales han sido uno de los problemas graves de la tradicional historiografía del arte. Para la demostración de la misma problemática, se ha escogido como objeto de análisis las interpretaciones tradicionales de la arquitectura conventual novohispano del siglo XVI. ¿Cómo mejorar las herramientas del estudio? Esto será una búsqueda y tarea constante del historiador del arte del siglo XXI. 